\title{
The Cognitive effects and academic Outcomes following Adenotonsillectomy in children with Obstructive Sleep Apnea (OSA)
}

\author{
Mohmed Gomaa ${ }^{1}$, Haytham Mamdouh ${ }^{1}$, Waffa Helmy ${ }^{1}$, Zeinab Khalf ${ }^{1}$, and Efat Zaki ${ }^{1}$ \\ ${ }^{1}$ Minia University Faculty of Medicine
}

May 12, 2020

\begin{abstract}
Background: Obstructive sleep apnea (OSA) in children is characterized by repeated airway obstructions during sleep. The peak incidence for pediatric OSA is during early childhood, in particular, the period between 2 and 8 years of age Aims/Objectives: The aim of this study to evaluate the effect of adenotonsillectomy (AT) on the scholastic achievement of children with Obstructive Sleep Apnea (OSA) to put a plan for proper management of those children. Material and Methods: 50 children were selected from 150 children suspected with OSA who came to our unit complaining from symptoms of (OSA) and seeking for adenotonsillectomy. 50 children well diagnosed as OSA due to adenotonsillar hypertrophy confirmed by polysomnography. a full history was taken from parents, audiological evaluation and All 50 children underwent a battery of neurocognitive tests containing process-oriented intelligence scales(Stanford Binet Intelligence scale and Illinois Test of psycholinguistic ability) pre and post adenotonsillectomy to show the effect of Adenotonsillectomy(AT) on scholastic achievement of children with Obstructive Sleep Apnea (OSA). Results: Children with OSAS had lower scores in neurocognitive tests(Illinois test and Stanford Binet intelligent scale) and Percentage (\%) of the child's scores of his subjects (Academic performance) indicating impaired neurocognitive function and school performance, but 8 months after adenotonsillectomy, the children with OSAS demonstrated statistical highly significant differences were obtained between the preoperative and postoperative examination of the study group as regards the symptoms of OSA, IQ and Mental age, auditory perceptual assessment (APA), PLA of VSM (Visual sequential memory), AA (Auditory association) VA (Visual association), AC (Auditory closure), VC (Visual closure), GC (Grammatic closure) and SB (Sound Blending) $(\mathrm{p}<0.001)$. Conclusions: the school performance and neurocognitive functions improve after Adenotonsillectomy indicating that the impaired school performance and neurocognitive functions are mostly reversible, at least 8 months following adenotonsillectomy.
\end{abstract}

\section{Hosted file}

manuscripte without authors.docx available at https://authorea.com/users/321058/articles/ 450582-the-cognitive-effects-and-academic-outcomes-following-adenotonsillectomy-inchildren-with-obstructive-sleep-apnea-osa

\section{Hosted file}

Table.docx available at https://authorea.com/users/321058/articles/450582-the-cognitiveeffects-and-academic-outcomes-following-adenotonsillectomy-in-children-with-obstructivesleep-apnea-osa 